\title{
Ex vivo evaluation of blood coagulation on endothelial glycocalyx-inspired surfaces using thromboelastography
}

\author{
Yanyi Zang ${ }^{1,2}$. Jessi R. Vlcek ${ }^{1}$. Jamie Cuchiaro ${ }^{3} \cdot$ Ketul C. Popat $^{1,4,5} \cdot$ Christine S. Olver $^{6} \cdot$ Matt J. Kipper $^{1,5,7}$. \\ Melissa M. Reynolds ${ }^{1,3,5}$
}

Received: 2 June 2021 / Revised: 12 August 2021 / Accepted: 23 August 2021 / Published online: 29 October 2021

(c) The Author(s), under exclusive licence to Springer Nature Switzerland AG 2021

\begin{abstract}
Purpose Present blood-contacting materials have not yet demonstrated to be effective in reducing blood coagulation without causing additional side effects clinically. We have developed an endothelial glycocalyx-inspired biomimetic surface that combines nanotopography, heparin presentation, and nitric oxide (NO)-releasing features. The resulting modified surfaces have already shown promise in reducing unfavorable blood-material interactions using platelet-rich plasma. In this study, the efficacy of modified surfaces for reducing coagulation of human whole blood was measured. In addition, the effects of leached polysaccharides and chemical modification of the modified surfaces were evaluated.

Methods Leached polysaccharides in the incubation solution were detected by a refractive index method to determine the potential influences of these modified surfaces on the blood coagulation observation. Chemical modifications by the nitrosation process on the polysaccharides in the modified surfaces were detected using attenuated total reflectance-Fourier transform infrared spectroscopy (ATR-FTIR). Clot formation parameters were measured using thromboelastography (TEG), a clinically relevant technique to evaluate whole blood coagulation.

Results No polysaccharides were detected in the heparinized polyelectrolyte multilayer-coated titania nanotube array surface $\left(\mathrm{TiO}_{2} \mathrm{NT}+\mathrm{PEM}\right)$ incubation solution; however, polysaccharides were detected from NO-releasing $\mathrm{TiO}_{2} \mathrm{NT}+\mathrm{PEM}$ surface $\left(\mathrm{TiO}_{2} \mathrm{NT}+\mathrm{PEM}+\mathrm{NO}\right)$ incubation solution both after the nitrosation process and after all $\mathrm{NO}$ was released. The structures of thiolated chitosan and heparin were altered by $t$-butyl nitrite. All heparin-containing surfaces were shown to slow or inhibit clot formation.
\end{abstract}

Conclusion This study is the first to evaluate these endothelial glycocalyx-inspired surfaces using clinically relevant parameters, as well as proposing potential influences of these modified surfaces on the inhibition of clot formation.

Keywords Nanotexture $\cdot$ Polysaccharides $\cdot$ Nitric oxide $\cdot$ Glycocalyx $\cdot$ Thromboelastography $\cdot$ Refractive index

\section{Introduction}

Since the first attempt of using the "Lane plate" for bone fracture repair in 1895 , metal implants have become increasingly popular because of their advantages, such as excellent

Melissa M. Reynolds

Melissa.Reynolds@colostate.edu

1 School of Biomedical Engineering, Colorado State University, Fort Collins, CO, USA

2 Present Address: Autonomous Reanimation and Evacuation Research Program, The Geneva Foundation, Brook City-Base, San Antonio, TX, USA

3 Department of Chemistry, Colorado State University, Fort Collins, CO, USA corrosion resistance, ease of sterilization, and others [1-4]. Currently, metal implants have been used in a variety of blood-contacting medical applications, for example, biosensors, vascular stents, and pacemakers. However, coagulation at the interface between human whole blood and the

4 Department of Mechanical Engineering, Colorado State University, Fort Collins, CO, USA

5 School of Advanced Materials Discovery, Colorado State University, Fort Collins, CO, USA

6 Veterinary Clinical Pathology Section, Colorado State University, Fort Collins, CO, USA

7 Department of Chemical and Biological Engineering, Colorado State University, Fort Collins, CO, USA 
surface of metal implants is still an unsolved limitation that impedes their performance [5]. The coagulation cascade starts when human whole blood interacts with implant surfaces, resulting in the deposition of blood plasma proteins such as fibrinogen. The adsorbed fibrinogen on the material surface is then converted into a fibrin clot in the presence of thrombin. The fibrin clots further induce platelet activation and aggregation, and lead to thrombus formation [6]. Without proper anticoagulant intervention, continuous blood clot formation places patients at high risk of medical deviceinduced thrombosis and may require an additional surgery to replace the implanted medical devices [7].

Current strategies involved in solving medical deviceinduced thrombosis include surface modification, anticoagulant administration, polymer coatings, and drug release [7-15]. Nanoscale and microscale surface features such as nanotextured surfaces have been shown to effectively reduce platelet activities and further inhibit thrombus formation on nitinol and titanium surfaces [8-10]. Heparin is a systemic anticoagulant that is commonly used in clinics either intravenously or subcutaneously to prevent thrombus formation. However, heparin can induce thrombocytopenia or even hemorrhagic complication, especially for patients with bleeding wounds $[11,12]$. Immobilized heparin on material surfaces or heparinized surfaces is another approach to improve the biocompatibility of medical devices, such as Hepacoat $^{\mathrm{TM}}$ on Bx Velocity Coronary Stents and Carmeda ${ }^{\circledR}$ BioActive surface on Cordis ${ }^{\circledR}$ stents [13-15]. The limitation of heparinized surfaces is that their inhibitory effects may not be enough to eliminate coagulation activation alone, and a supplemental anticoagulant therapy is required [16]. Drugeluting surfaces also improve medical device performance and are commercially available. However, the duration of drug release may not be tuned to individual patient needs [17]. These approaches still have limitations of both performance and patient risk; therefore, new strategies are needed.

Endothelial glycocalyx-inspired multifunctional surfaces combine several surface features, including nanotextured and microtextured surfaces, heparin and chitosan polyelectrolyte multilayer (PEM) coatings, and the release of nitric oxide (NO) [18]. First, a bare titanium (Ti) surface was fabricated into a titania nanotube surface $\left(\mathrm{TiO}_{2} \mathrm{NT}\right)$ using an electrochemical method to form $\mathrm{TiO}_{2} \mathrm{NT}$. Second, positively charged chitosan and negatively charged heparin were coated onto the nanotube surface to produce $\mathrm{TiO}_{2} \mathrm{NT}+\mathrm{PEM}$. Finally, the surface coating was nitrosated to confer the ability to release $\mathrm{NO}$ molecules, yielding $\mathrm{TiO}_{2} \mathrm{NT}+\mathrm{PEM}+\mathrm{NO}$. The nanotextured surface has been shown to deactivate plasma components [10]. The polyelectrolyte multilayer coating was designed to mimic the glycosaminoglycan presentation in the endothelial glycocalyx, which may prevent blood protein adsorption and fibrin clot formation [19-21]. The combination of nanotextured surfaces with PEM coating has been shown to reduce platelet adhesion and activation $[22,23]$. Nitric oxide, an endogenous signaling molecule, is well-known for its antiplatelet and anticoagulation properties [24]. Multiple NO-releasing surfaces have been shown to mitigate blood protein deposition, and inhibit platelet adhesion and activation [25-30]. This three-in-one promising surface has been previously proven to significantly inhibit platelet adhesion and activation in contact with human platelet-rich plasma [18]. However, this coating has not been evaluated in a real-time manner using human whole blood.

Herein, we report the first real-time clot formation evaluation on an NO-releasing PEM coating on a titania nanotube array surface using human whole blood. In this study, thromboelastography (TEG) was performed. TEG has been widely used in various applications, ranging from coagulation management in clinical testing to the evaluation of newly designed biomaterials [31-33]. In addition, TEG allows the localized measurement of whole blood coagulation on a material surface, including initiation of clot formation, rate of clot formation, and clot strength. This is an advancement compared to plasma-based coagulation assays which only allow evaluation of the initiation of clot formation, and therefore may not be sensitive nor specific for a surface's effect on coagulation. Blood clot formation was not detected after blood was incubated with $\mathrm{TiO}_{2} \mathrm{NT}+\mathrm{PEM}$ surfaces for either $15 \mathrm{~min}$ or $60 \mathrm{~min}$. Blood clotting was delayed after blood was incubated with $\mathrm{TiO}_{2} \mathrm{NT}+\mathrm{PEM}+\mathrm{NO}$ surfaces for either $15 \mathrm{~min}$ or $60 \mathrm{~min}$; however, clots still formed in the blood. Based on these results, we further conducted analyses on the incubation solution to detect the presence of released polysaccharides using a refractive index (RI) method. We also identified chemical modification of chitosan thioglycolic acid (chitosan-TGA) and heparin by the nitrosation process using attenuated total reflectance-Fourier transform infrared spectroscopy (ATR-FTIR) [34]. This work reveals which features of these novel glycocalyx-inspired surfaces influence whole blood clotting kinetics, and provides insights into the design of biomimetic blood-compatible surfaces.

\section{Materials and methods}

\section{Materials}

All chemicals and solvents were purchased from commercial vendors and used without further purification unless otherwise noted. CP Grade 1 Surplus Titanium sheet $\left(0.025^{\prime \prime}\right.$ thickness) was purchased from Titanium Joe (Kingston, Ontario, Canada). Platinum foil was purchased from Surepure Chemetals (Florham Park, NJ, USA). Diethylene glycol (DEG; 99\%) and hydrofluoric acid (HF; 48-51\%) were purchased from Alfa Aesar (Tewksbury, MA, USA). 
Low molecular weight chitosan $(96.1 \%$ deacetylated, $50-190 \mathrm{kDa}$ ), thioglycolic acid ( $\geq 98 \%)$, tris(2-carboxyethyl)phosphine hydrochloride ( $\geq 98 \%$ ), and tert-butyl nitrite $(90 \%)$ were purchased from Sigma-Aldrich (St. Louis, MO, USA). $N$-(3-Dimethylaminopropyl)- $N$ '-ethylcarbodiimide hydrochloride ( $\geq 99 \%)$ was purchased from Chem-Impex International (Wood Lawn, IL, USA). Heparin sodium was purchased from Celsus Laboratories, Inc. (from porcine intestinal mucosa, $14.4 \mathrm{kDa}, 12.5 \%$ sulfur; Cincinnati, $\mathrm{OH}$, USA). Acetic acid $(99+\%)$ was purchased from ACROS organics (Geel, Belgium). Corning ${ }^{\text {TM }} 0.22-\mu \mathrm{m}$ PES vacuum filter/storage systems were purchased from Corning (Corning, NT, USA). Spectra/Por ${ }^{\mathrm{TM}} 8000$ MWCO membrane tubing, methanol, ethanol, and $50-\mathrm{mL}$ conical tubes were purchased from Fisher Scientific (Hampton, NH, USA). Diethyl ether was purchased from EMD Millipore (Burlington, MA, USA). Millipore water $(18.2 \mathrm{M} \Omega \cdot \mathrm{cm})$ was used for all experiments.

\section{Surface preparation and characterization}

Surfaces were prepared based on a previously reported method $[10,18,35]$. Briefly, $\mathrm{TiO}_{2} \mathrm{NT}$ was fabricated through a 55-V 22-h DEG/HF/water-based electrochemical anodization process with titanium serving the anode and platinum serving the cathode. Chitosan-TGA was synthesized by adding $1.5 \mathrm{~mL}$ of thioglycolic acid and $3.8 \mathrm{~g}$ of $\mathrm{N}$-(3dimethylaminopropyl)- $N$ '-ethylcarbodiimide hydrochloride into the mixture of $100 \mathrm{~mL}$ chitosan solution $(1.0 \mathrm{~g}$ of chitosan in $100 \mathrm{~mL}$ of water) and $1.0 \mathrm{~mL}$ of acetic acid. The resulting solution was dialyzed against $4 \mathrm{~L}$ of water with $0.25 \mathrm{M} \mathrm{HCl}$ in $8000 \mathrm{MWCO}$ tubing at $\mathrm{pH} 4-5$ for $24 \mathrm{~h}$ in the absence of light. After dialysis, $0.1 \mathrm{~g}$ of tris(2carboxyethyl)phosphine hydrochloride was added into the solution. The solution was further dialyzed again in 8000 MWCO tubing against $4 \mathrm{~L}$ of water with $0.25 \mathrm{M} \mathrm{HCl}$ at $\mathrm{pH} 4-5$ for 7 days ( $50 \mathrm{~g}$ of $\mathrm{NaCl}$ was added into water for the first 3 days) without light. After dialysis, the resulting contents in the tubing were freeze-dried for 4 days in the absence of light. Lyophilized chitosan-TGA and heparin were dissolved into $0.2 \mathrm{M}$ acetate buffer $(\mathrm{pH}=4.5)$ to form a $0.01 \mathrm{M}$ chitosan-TGA polymer solution and $0.01 \mathrm{M}$ heparin polymer solution, respectively. Both polymer solutions were filtered through Corning ${ }^{\mathrm{TM}} 0.22-\mu \mathrm{m}$ PES vacuum filter/ storage systems. Acidified rinse solution was prepared by adjusting Millipore water $\mathrm{pH}$ to 4 using glacial acetic acid. Positively charged chitosan-TGA and negatively charged heparin were coated for 10 bilayers onto a $\mathrm{TiO}_{2} \mathrm{NT}$ surface using a layer-by-layer coating process. The $\mathrm{TiO}_{2} \mathrm{NT}$ samples $(1.0 \mathrm{~cm} \times 1.0 \mathrm{~cm})$ were each placed in the wells of a $24-w e l l$ plate. For each bilayer, $1 \mathrm{~mL}$ of solution was added into each well that contained $\mathrm{TiO}_{2} \mathrm{NT}$ surface in the following order: acidified rinse solution, chitosan-TGA polymer solution, acidified rinse solution, and heparin solution. Between each solution, the well plate was shaken for $5 \mathrm{~min}$ and the solution was removed by aspiration. After 10 bilayers were applied, the surface in each well was rinsed with $1 \mathrm{~mL}$ of acidified rinse solution and dehydrated using a series of ethanol concentrations $(50 \%, 70 \%, 90 \%, 100 \%$, and $100 \%)$ with $5 \mathrm{~min}$ for each concentration. The surfaces were then dried in a chemical fume hood before nitrosation. For the nitrosation process, all steps were performed in the dark. Each surface was soaked in $300 \mu \mathrm{L}$ of tert-butyl nitrite overnight on a shaker. The next day, surfaces were rinsed with $300 \mu \mathrm{L}$ of methanol followed by $300 \mu \mathrm{L}$ of diethyl ether before being dried under vacuum for $30 \mathrm{~min}$. Nitrosated surfaces were then covered with aluminum foil and used within $1 \mathrm{~h}$. Surfaces were characterized using scanning electron microscopy (SEM) for surface morphology $(n=3)$ and nitric oxide analyzer (NOA) for NO-releasing measurement $(n=3)$.

\section{Detection of released polysaccharides in the soaking solution via a refractive index (RI) method}

Refractive index detection was carried out on an Agilent 1260 Infinity II HPLC equipped with RI detector via direct sample injection. Data were analyzed using Agilent OpenLab CDS (version 3.4.0) software. The mobile phase used was water. A flow rate of $0.3 \mathrm{~mL} / \mathrm{min}$ and a $10-\mu \mathrm{L}$ injection volume ( $n=5$, each analyzed in triplicate) were used. The detector temperature was set to $30^{\circ} \mathrm{C}$ and in the positive polarity mode. $\mathrm{Ti}, \mathrm{TiO}_{2} \mathrm{NT}, \mathrm{TiO}_{2} \mathrm{NT}+\mathrm{PEM}$, and one set of $\mathrm{TiO}_{2} \mathrm{NT}+\mathrm{PEM}+\mathrm{NO}$ surfaces were soaked into $0.5 \mathrm{~mL}$ of water for $60 \mathrm{~min}$ at $37{ }^{\circ} \mathrm{C}$ with gentle shaking. Another set of $\mathrm{TiO}_{2} \mathrm{NT}+\mathrm{PEM}+\mathrm{NO}$ surfaces was incubated overnight to ensure NO was fully released from the surfaces. These surfaces were then submerged in $0.5 \mathrm{~mL}$ of water for 60 min at $37^{\circ} \mathrm{C}$ with gentle shaking before performing the RI measurement. To distinguish if the RI method is specific to leached heparin, $200 \mu \mathrm{g} / \mathrm{mL}$ working solutions of heparin, nitrosated heparin, chitosan-TGA, and nitrosated chitosan-TGA were analyzed and the instrument responses were compared. These $200 \mu \mathrm{g} / \mathrm{mL}$ working solutions were prepared in DI water.

\section{Detection of chemical modification by nitrosation process via attenuated total reflectance-Fourier transform infrared (ATR-FTIR)}

Nitrosated samples were submerged in tert-butyl nitrite overnight, dried, and rinsed with methanol and ethyl ether. The samples were then air-dried shielded from light for at least $24 \mathrm{~h}$ before analysis. ATR-FTIR spectra were collected using a Thermo Nicolet 6700 spectrometer equipped with a diamond ATR crystal between 650 and $4000 \mathrm{~cm}^{-1}$. Solid 
samples of heparin, nitrosated heparin, chitosan-TGA, and nitrosated chitosan-TGA were analyzed and their spectra compared. Representative spectra were reported.

\section{Human whole blood collection}

This research was approved by the Colorado State University Institutional Review Board for the protection of human subjects with protocol \# 19-9039H and the Colorado State University Institutional Biosafety Committee for the utilization of biohazardous materials with protocol \# 14-070B. In total, three individuals donated blood for this study. Human whole blood was collected at Colorado State University Health and Medical Center from healthy donors who were lacking coagulopathies and had not used thromboxane inhibitors for at least 2 weeks. Blood was drawn into $4.5-\mathrm{mL}$ citrated BD Vacutainers ${ }^{\circledR}$ venous blood collection tubes $(12.35 \mathrm{mg}$ of sodium citrate, $2.21 \mathrm{mg}$ of citric acid). After blood collection, human whole blood in each tube was transferred into a $50-\mathrm{mL}$ conical tube and allowed to rest for $20 \mathrm{~min}$ prior to use. All blood was used within $4 \mathrm{~h}$ following collection time.

\section{Thromboelastography (TEG)}

One milliliter of citrated human whole blood was incubated with modified surfaces in microcentrifuge tubes for $15 \mathrm{~min}$ and $60 \mathrm{~min}$ at room temperature, and unmodified $\mathrm{Ti}$ surfaces were used as controls ( $\mathrm{n} \geq 5$ batches of surfaces). After incubation, $340 \mu \mathrm{L}$ of citrated human whole blood was transferred into TEG disposable cups with $20 \mu \mathrm{L}$ of $0.2 \mathrm{M}$ calcium chloride. TEG was then performed without activating reagents at $37{ }^{\circ} \mathrm{C}$ until clot maximum amplitude (MA) was detected or until $60 \mathrm{~min}$ after TEG was started. Several clinically relevant clot formation parameters were recorded (Supporting Information Figure S1) including reaction time $(R)$ which is the amount of time required for the first detection of a 2-mm amplitude clot in blood, initial clot formation time $(K)$ which is the amount of time required to progress to a 20-mm amplitude clot, the angle between baseline and the tangential line of $R$ ( $\alpha$-angle) which shows the speed of fibrin formation and cross-linking comparing to the "thrombin burst" in the cell-based model, and maximal amplitude (MA) which is the detected clot strength and relates to clot stability.

\section{Statistical analysis}

One-way analysis of variance (ANOVA) followed by post hoc Tukey-Kramer multiple comparison test at a 95\% confidence interval $(p<0.05)$ was used to evaluate statistical differences. All reported values were expressed as mean \pm standard deviation.

\section{Results and discussion}

\section{Surface characterization}

SEM images at two different magnifications of $\mathrm{Ti}, \mathrm{TiO}_{2} \mathrm{NT}$, $\mathrm{TiO}_{2} \mathrm{NT}+\mathrm{PEM}$, and $\mathrm{TiO}_{2} \mathrm{NT}+\mathrm{PEM}+\mathrm{NO}$ surfaces are shown in Fig. 1. The nanotubular structures on the $\mathrm{TiO}_{2} \mathrm{NT}$, $\mathrm{TiO}_{2} \mathrm{NT}+\mathrm{PEM}$, and $\mathrm{TiO}_{2} \mathrm{NT}+\mathrm{PEM}+\mathrm{NO}$ surfaces were identical since they were all fabricated from Ti surfaces. Anodized titanium nanotubular surfaces are known for their bioactivity such as the promotion of cellular responses, cell
Ti
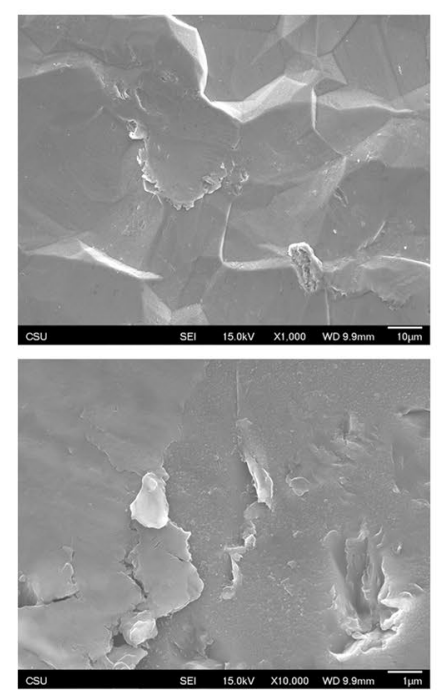

$\mathrm{TiO}_{2} \mathrm{NT}$
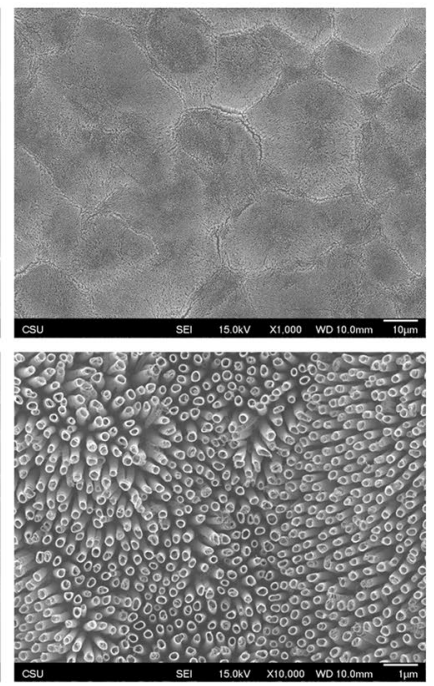

$\mathrm{TiO}_{2} \mathrm{NT}+\mathrm{PEM}$
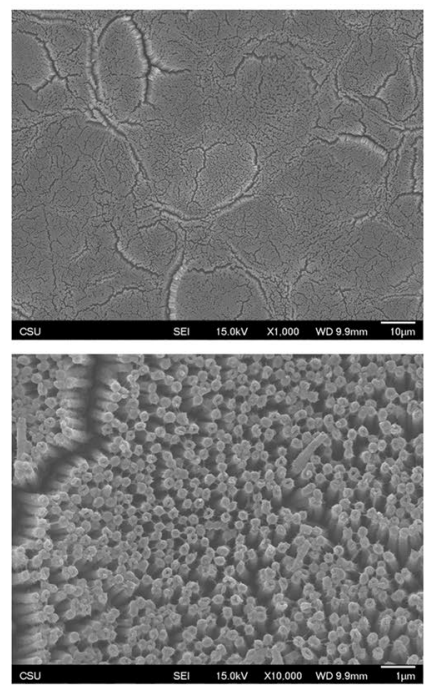

$\mathrm{TiO}_{2} \mathrm{NT}+\mathrm{PEM}+\mathrm{NO}$

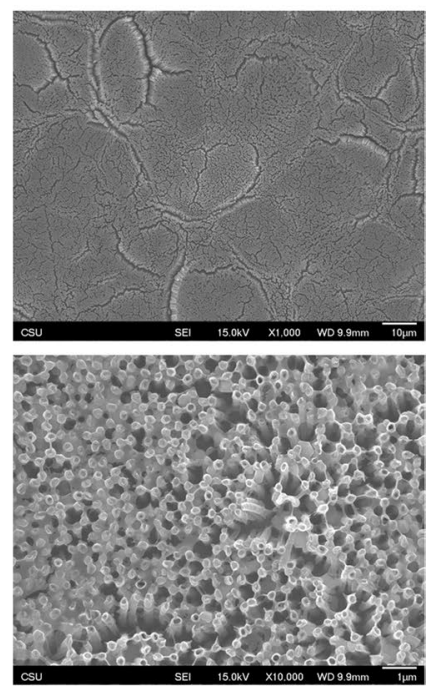

Fig. 1 Representative SEM images of $\mathrm{Ti}, \mathrm{TiO}_{2} \mathrm{NT}, \mathrm{TiO}_{2} \mathrm{NT}+\mathrm{PEM}$, and $\mathrm{TiO}_{2} \mathrm{NT}+\mathrm{PEM}+\mathrm{NO}$ surfaces. Scale bars in the upper row of images are all $10 \mu \mathrm{m}$. Scale bars in the lower row of images are all $1 \mu \mathrm{m}$ 
adhesion, cell differentiation, and other properties in various implant applications. [36, 37] In addition, anodized titanium nanotubes have been shown to significantly decrease platelet adhesion and bacterial adhesion independently or in combination with other substances. $[10,18,38]$ The performance and function of anodized titanium greatly depend on the diameter and size of the nanotube structure [39, 40]. In this study, the size and diameter of the nanotube array were selected based on a published literature which showed promising results in the inhibition of platelet activity. [18] The PEM coating on both $\mathrm{TiO}_{2} \mathrm{NT}+\mathrm{PEM}$ and $\mathrm{TiO}_{2} \mathrm{NT}+\mathrm{PEM}+\mathrm{NO}$ surfaces covered individual nanotubes and blocked the pores; however, the coating did not change the nanotube structure. There was no distinct difference between $\mathrm{TiO}_{2} \mathrm{NT}+\mathrm{PEM}$ and $\mathrm{TiO}_{2} \mathrm{NT}+\mathrm{PEM}+\mathrm{NO}$ surfaces, which indicated that the nitrosation process did not visually affect the PEM coating.

The representative real-time and cumulative NO release from $\mathrm{TiO}_{2} \mathrm{NT}+\mathrm{PEM}+\mathrm{NO}$ surfaces is shown in Supporting Information Figure S2. Both real-time and cumulative NO release showed that the majority of NO was released from the surface during the first $25 \mathrm{~min}$ and nearly no NO was released after $40 \mathrm{~min}$. Nitric oxide release from healthy blood vessel endothelial cells exhibits $0.5-4 \times 10^{-10} \mathrm{~mol} \mathrm{~cm}^{-2} \mathrm{~min}^{-1}$ or $1.25-10 \mathrm{nmol} \mathrm{cm} \mathrm{cm}^{-2}$ if released for $25 \mathrm{~min}$ [41]. In this study, $\mathrm{TiO}_{2} \mathrm{NT}+\mathrm{PEM}+\mathrm{NO}$ surfaces were able to release approximately $4 \mathrm{nmol} \mathrm{cm}^{-2}$ of NO during the first $25 \mathrm{~min}$, which is within the range of NO release from endothelial cells. The amount of NO delivery from this study has been increased tenfold compared to our previously published work [18]. A previous study has showed that a $13.7 \times 10^{-10} \mathrm{~mol} \mathrm{~cm}^{-2} \mathrm{~min}^{-1}$ of NO release or $42.5 \mathrm{nmol} \mathrm{cm}^{-2}$ if released for $25 \mathrm{~min}$ is expected to actively inhibit the coagulation cascade in extracorporeal life support in a rabbit model [42]. The amount of optimal NO release from different NO-donor platforms for human in vivo applications is still unknown. Changes on PEM coating thickness, NO-donor selection, and nitrosation process for optimal NO release require further investigation.

\section{Detection of released polysaccharides in soaking solution via refractive index (RI) method}

The suitability of the RI detection method was calibrated using serial dilutions of a heparin stock solution. The detector signal was linear between 3000 and 120,000 nRI*min $\left(R^{2}=0.9998\right)$, corresponding to a heparin concentration of $15 \mu \mathrm{g} / \mathrm{mL}-10 \mathrm{mg} / \mathrm{mL}$ (Supporting Information Figure S3). The limit of detection (LOD) was defined as three times the standard deviation of the blank and the limit of quantitation was defined as ten times the standard deviation of the blank. The method LOD and LOQ were $900 \mathrm{nRI} *$ min and 3000 nRI*min, respectively.
The detection method was not specific to heparin when the RI signals from $200 \mu \mathrm{g} / \mathrm{mL}$ solutions of heparin, nitrosated heparin, chitosan-TGA, and nitrosated chitosan-TGA were compared. The RI signals detected from the $200 \mu \mathrm{g} /$ $\mathrm{mL}$ nitrosated heparin, chitosan-TGA, and nitrosated chitosan-TGA solutions were $25 \%, 46 \%$, and $105 \%$ higher, respectively, than that from the heparin solution of the same concentration. For this reason, RI data of leached polysaccharides in the soaking solutions is reported as detector signal $(\mathrm{nRI} * \mathrm{~min})$ rather than concentration $(\mu \mathrm{g} / \mathrm{mL})$.

Blood coagulation may be affected by direct contact of polysaccharides that are released into the soaking solution, bound onto surfaces, or both. Polysaccharides released from the modified surfaces, which were present in the soaking solution, were detected by the RI method. $\mathrm{Ti}$ and $\mathrm{TiO}_{2} \mathrm{NT}$ surfaces were included as negative controls, in addition to the heparin-containing surfaces. As shown in Table 1, signals from $\mathrm{TiO}_{2} \mathrm{NT}+\mathrm{PEM}$ soaking samples, as well as both $\mathrm{Ti}$ and $\mathrm{TiO}_{2} \mathrm{NT}$ controls, were below the method limit of detection. The $\mathrm{TiO}_{2} \mathrm{NT}+\mathrm{PEM}+\mathrm{NO}$ incubation samples produced signals of $18,000 \pm 2000 \mathrm{nRI} * \mathrm{~min}$ and 17,000 $\pm 2000 \mathrm{nRI} *$ min, after nitrosation and after all NO was released, respectively.

To determine whether the nitrosation process or nitrogen species in the solution after all NO was released affects the release of polysaccharides, two sets of $\mathrm{TiO}_{2} \mathrm{NT}+\mathrm{PEM}+\mathrm{NO}$ surfaces were evaluated: $\mathrm{TiO}_{2} \mathrm{NT}+\mathrm{PEM}+\mathrm{NO}$ surfaces immediately after nitrosation and $\mathrm{TiO}_{2} \mathrm{NT}+\mathrm{PEM}+\mathrm{NO}$ surfaces after all $\mathrm{NO}$ was released. The signals of both sets of $\mathrm{TiO}_{2} \mathrm{NT}+\mathrm{PEM}+\mathrm{NO}$ soaking solution were observed, which indicated the presence of polysaccharides (Table 1). Since signal height of both $\mathrm{TiO}_{2} \mathrm{NT}+\mathrm{PEM}+\mathrm{NO}$ soaking solutions was similar, it can be inferred that nitrogen species in the solution after all NO was released does not influence polysaccharide release. There was an increasing signal from the soaking solution of nitrosated $\mathrm{TiO}_{2} \mathrm{NT}+\mathrm{PEM}+\mathrm{NO}$ surfaces compared to the soaking solution of $\mathrm{TiO}_{2} \mathrm{NT}+\mathrm{PEM}$ surfaces, establishing that the nitrosation process is altering the degree of polysaccharide release. However, as shown in Table 2, the RI method was sensitive to all polysaccharides

Table 1 Refractive index signal (nRI*min) of modified surface soaking samples and controls

\begin{tabular}{ll}
\hline Soaking samples & $\begin{array}{l}\text { Refractive index } \\
\text { signal (nRI*min) }\end{array}$ \\
\hline $\mathrm{Ti}$ (control) & $<\mathrm{LOD}$ \\
$\mathrm{TiO}_{2} \mathrm{NT}$ (control) & $<\mathrm{LOD}$ \\
$\mathrm{TiO}_{2} \mathrm{NT}+\mathrm{PEM}$ & $<\mathrm{LOD}$ \\
$\mathrm{TiO}_{2} \mathrm{NT}+\mathrm{PEM}+\mathrm{NO}$ (after nitrosation) & $18,000 \pm 2000$ \\
$\mathrm{TiO}_{2} \mathrm{NT}+\mathrm{PEM}+\mathrm{NO}$ (after all NO was released) & $17,000 \pm 2000$ \\
\hline
\end{tabular}


Table 2 Refractive index signal (nRI*min) corresponding to $200 \mu \mathrm{g} /$ $\mathrm{mL}$ solutions of heparin, nitrosated heparin, chitosan-TGA, and nitrosated chitosan-TGA

\begin{tabular}{lll}
\hline Sample $(200 \mu \mathrm{g} / \mathrm{mL}$ solution) & $\begin{array}{l}\text { Refractive index } \\
\text { signal (nRI*min) }\end{array}$ & $\begin{array}{l}\% \text { Relative } \\
\text { heparin } \\
\text { signal }\end{array}$ \\
\hline Heparin & $49,900 \pm 300$ & - \\
Nitrosated heparin & $62,100 \pm 200$ & $125 \%$ \\
Chitosan-TGA & $72,900 \pm 300$ & $146 \%$ \\
Nitrosated chitosan-TGA & $102,200 \pm 100$ & $205 \%$ \\
\hline
\end{tabular}

potentially present in the soaking solution such as heparin, chitosan, nitrosated heparin, and nitrosated chitosan. Further experimentation is required to quantify individual polysaccharides present in the soaking solution such as anion-exchange chromatography or size-exclusion chromatography, as well as to identify the exact mechanism that is causing the increased release of polysaccharides after nitrosation.
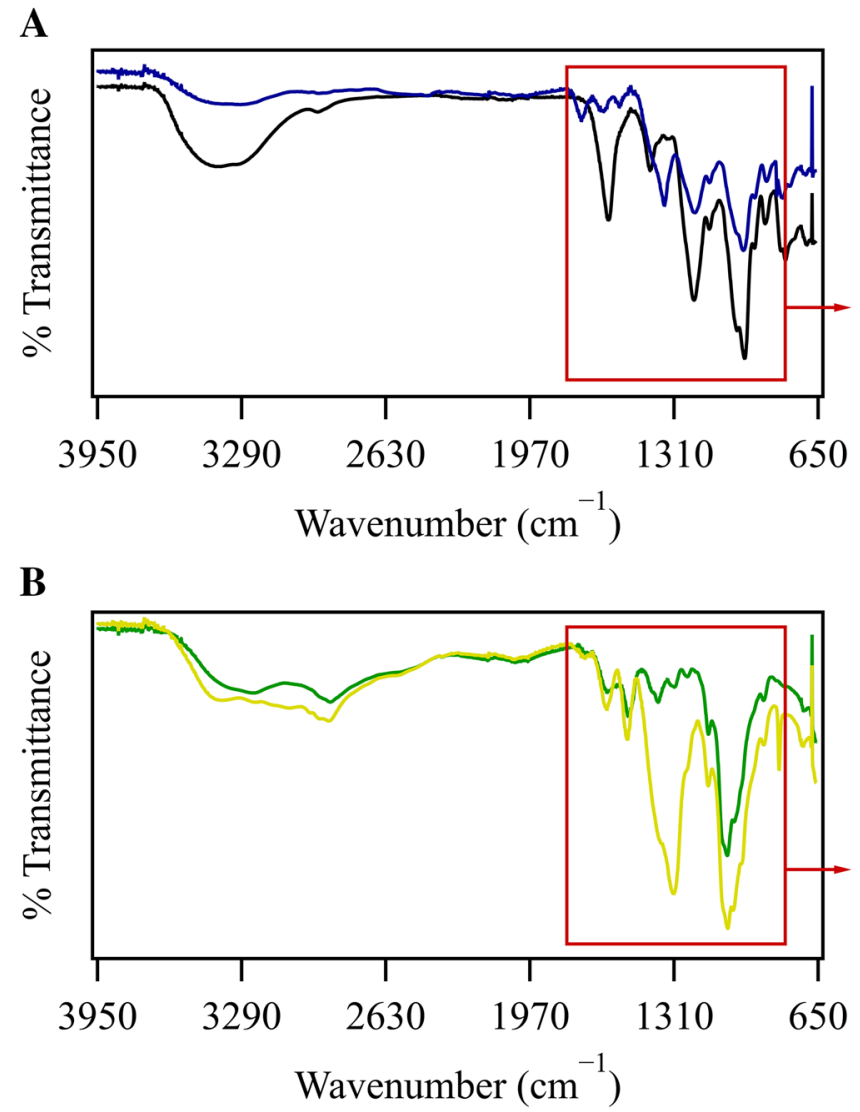

Fig. 2 ATR-FTIR spectra of heparin (black), nitrosated heparin (purple), chitosan-TGA (green), and nitrosated chitosan-TGA (yellow). A Full spectra of heparin and nitrosated heparin with fingerprint region.
Detection of chemical modification by the nitrosation process via attenuated total reflectance-Fourier transform infrared (ATR-FTIR)

The effects of tert-butyl nitrite on chitosan-TGA and heparin structures were independently evaluated by ATR-FTIR. As shown in Fig. 2, both the structures of chitosan-TGA and heparin were altered by tert-butyl nitrite. Chitosan-TGA has been developed and used as an NO-releasing agent [18, 43]. Nitrous acid has been shown to modify the structures of heparin and chitosan at low $\mathrm{pH}[44,45]$.

The hydrolysis of tert-butyl nitrite may generate nitrous acid which can impact the structure of heparin. However, structural modification of heparin is only observed when the $\mathrm{pH}$ is lower than $2.5[44,46]$. The disappearance of the vibrational mode at $1610 \mathrm{~cm}^{-1}$ in the heparin spectrum and the appearance of a weak vibrational mode at $1734 \mathrm{~cm}^{-1}$ in the nitrosated heparin spectrum indicate a structural change caused by the tert-butyl nitrite. Similarly, the appearance of the vibrational mode at $1311 \mathrm{~cm}^{-1}$ in the nitrosated chitosanTGA spectrum indicates a structural change after exposure
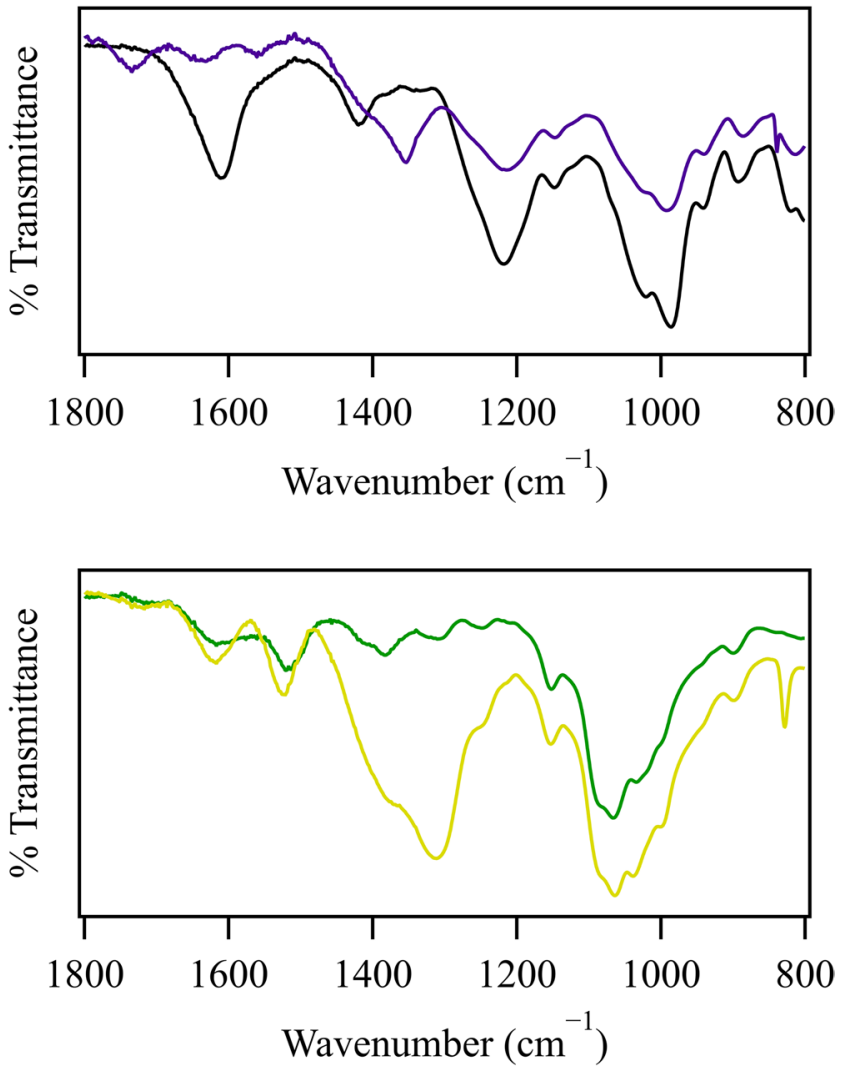

B Full spectra of chitosan-TGA and nitrosated chitosan-TGA with fingerprint region 
to tert-butyl nitrite. The sharp spike occurring at $650 \mathrm{~cm}^{-1}$ is an instrument artifact. It is possible that the structural change observed in heparin will impede its ability to activate antithrombin and further inhibit the coagulation cascade. Additionally, the nitrosation process may disturb the surface layer of heparin and cause polysaccharides to disperse into solution. This physically changes the surface roughness and might further affect the coagulation cascade [47].

\section{Evaluation of real-time blood clot formation on modified surfaces by thromboelastography}

In the thromboelastogram (TEG), the reaction time $(R)$ is the time needed for initial fibrin formation by activating the intrinsic pathway and is dependent on enzymatic factor activity. In healthy blood that has not been exposed to anticoagulants, reaction times can range between 5 and $10 \mathrm{~min}$ in non-activated TEG. A 2-mm amplitude of blood clot formation was reached on each surface type after 15and 60-min incubation in human whole blood, except for the $\mathrm{TiO}_{2} \mathrm{NT}+\mathrm{PEM}$ surfaces (Fig. 3). The time until clot formation was significantly prolonged on $\mathrm{TiO}_{2} \mathrm{NT}+\mathrm{PEM}+\mathrm{NO}$ surfaces after 15-min incubation (13.1 $\pm 2.8 \mathrm{~min})$ compared to $\mathrm{Ti}(7.7 \pm 1.1 \mathrm{~min})$ and $\mathrm{TiO}_{2} \mathrm{NT}(6.8 \pm 1.8 \mathrm{~min})$ surfaces (Fig. 3A). For the 60-min incubation samples, the time to initial clot formation $(R)$ was significantly prolonged on $\mathrm{TiO}_{2} \mathrm{NT}+\mathrm{PEM}+\mathrm{NO}$ surfaces after 60 -min incubation $(17.5 \pm 8.6 \mathrm{~min})$ compared to $\mathrm{Ti}(5.6 \pm 1.0 \mathrm{~min})$ and $\mathrm{TiO}_{2} \mathrm{NT}(3.8 \pm 0.0 \mathrm{~min})$ surfaces (Fig. 3B). From the reaction time values, nanotexturing of the surfaces does not seem to influence initial clot formation. It is unclear why the $\mathrm{TiO}_{2} \mathrm{NT}+\mathrm{PEM}$ surfaces inhibit coagulation while the $\mathrm{TiO}_{2} \mathrm{NT}+\mathrm{PEM}+\mathrm{NO}$ surfaces allow for coagulation. The addition of the NO should further inhibit clot formation, but this was not observed in this study. Several factors may contribute to this observation, such as inactivated heparin after nitrosation, resumption of platelet activities after all $\mathrm{NO}$ was released, NO alteration of fibrinogen or thrombin changing their susceptibility to heparin, or other effects.

Heparin has been widely used clinically as an anticoagulant. [48-50] It exhibits anticoagulant activities, either bound on top of the coating or released from the coating. In addition to the heparin enriched at the surface, heparin was possibly released from the PEMs and directly interacted with the blood in the solution. While both $\mathrm{TiO}_{2} \mathrm{NT}+\mathrm{PEM}$ and $\mathrm{TiO}_{2} \mathrm{NT}+\mathrm{PEM}+\mathrm{NO}$ surfaces leached polysaccharides, the concentration of polysaccharides released into the $\mathrm{TiO}_{2} \mathrm{NT}+\mathrm{PEM}+\mathrm{NO}$ surface soaking solution was approximately 200 -fold more than that released into the $\mathrm{TiO}_{2} \mathrm{NT}+\mathrm{PEM}$ surface soaking solution. Therefore, the $\mathrm{TiO}_{2} \mathrm{NT}+\mathrm{PEM}+\mathrm{NO}$ surface soaking solution should have a higher heparin concentration than the $\mathrm{TiO}_{2} \mathrm{NT}+\mathrm{PEM}$
Fig. 3 Reaction time $(R)$ of modified surfaces after 15-min and 60-min incubation in human whole blood $(n \geq 5$ batches of surfaces, * indicates $p<0.05,>60 \mathrm{~min}$ indicates no endpoint value was provided by TEG during 60 -min test). A Reaction time (R): 15 min incubation. B Reaction time (R): 60 min incubation
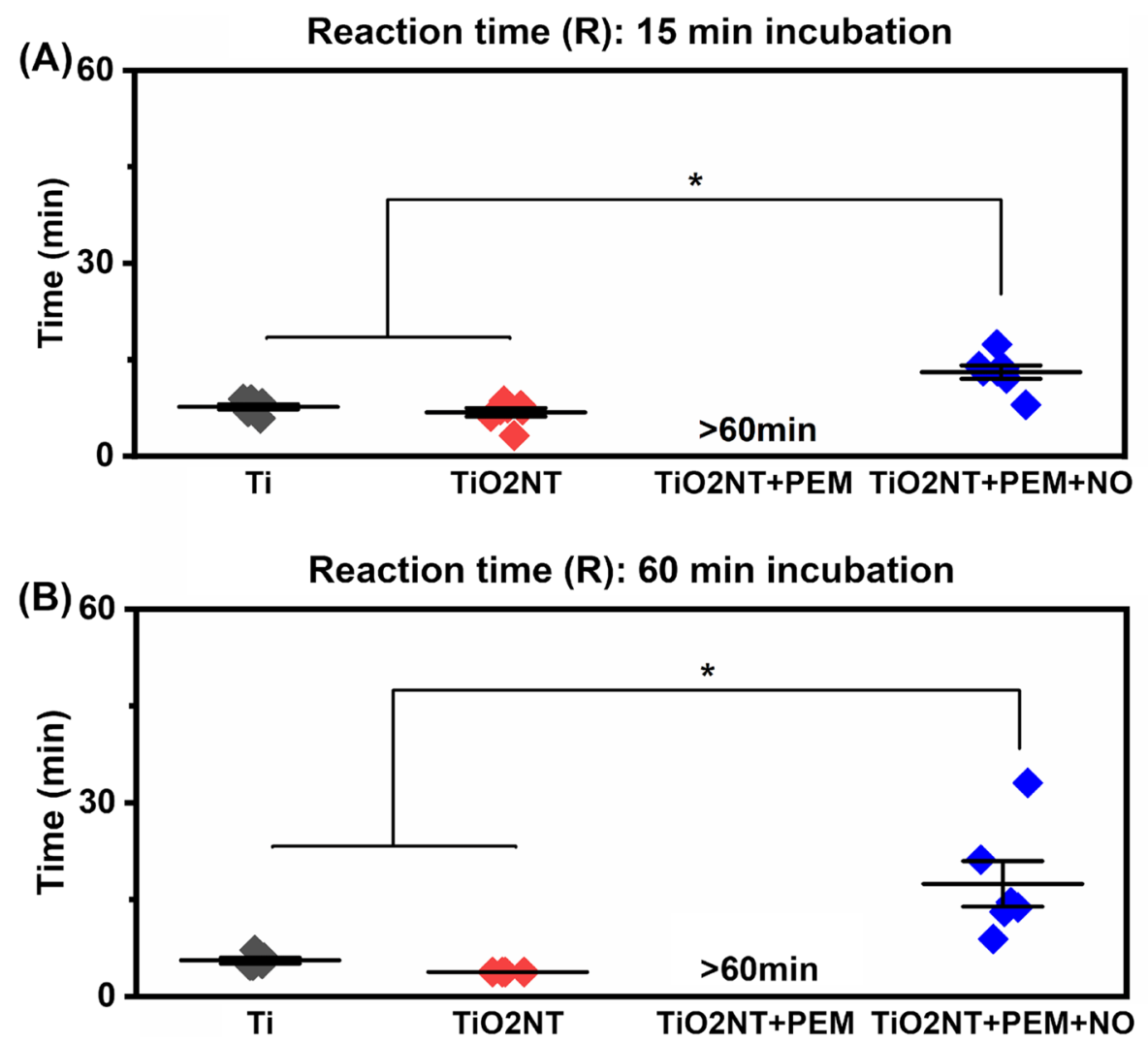
Fig. 4 Initial clot formation time $(K)$ of modified surfaces after 15-min and 60-min incubation in human whole blood $(n \geq 5$ batches of surfaces, * indicates $p<0.05$, N/A indicates no endpoint value was provided by TEG during 60 -min test). A Initial clot formation time (K): 15 min incubation. B Initial clot formation time (K): $60 \mathrm{~min}$ incubation
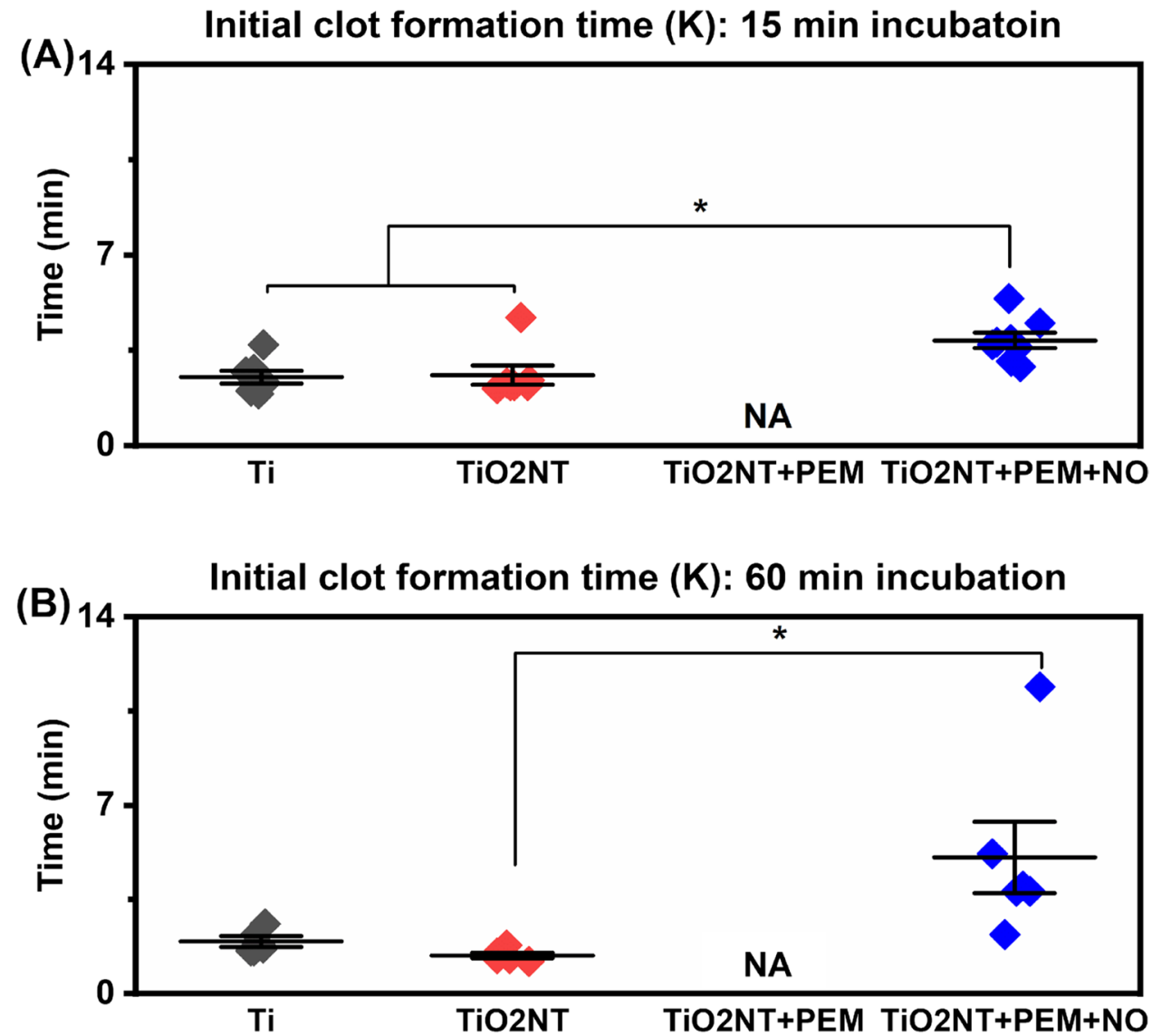

surface soaking solution. The additional heparin in solution should have further inhibited coagulation. On the contrary, the $\mathrm{TiO}_{2} \mathrm{NT}+\mathrm{PEM}$ surfaces that released less heparin were found to inhibit coagulation. However, from the ATR-FTIR data shown above, the nitrosation process itself structurally modified heparin on the $\mathrm{TiO}_{2} \mathrm{NT}+\mathrm{PEM}+\mathrm{NO}$ surfaces and/ or in the incubation solution, which could inactivate heparin and further inhibit its anticoagulation activity on blood.

Chitosan and its derivatives are effective hemostatic agents that enhance the blood coagulation cascade to accelerate the wound healing process [51-57]. At low pH, the positively charged ammonium groups on chitosan and its derivatives interact with negatively charged proteins and glycolipids in the red blood cell membrane, inducing the aggregation of red blood cells $[52,58]$. Previous studies also show that chitosan and its derivatives are able to trigger platelet adhesion and aggregation, through the interaction between positively charged chitosan and negatively charged phosphatidyl serine in the platelet membrane [59-61]. The complete hemostasis mechanism of chitosan and its derivatives is still unclear [62]. In this study, both $\mathrm{TiO}_{2} \mathrm{NT}+\mathrm{PEM}$ and $\mathrm{TiO}_{2} \mathrm{NT}+\mathrm{PEM}+\mathrm{NO}$ surfaces have chitosan layers, but $\mathrm{TiO}_{2} \mathrm{NT}+\mathrm{PEM}$ did not induce coagulation. For both surface groups, heparin is the top coating layer for the 10-bilayer PEMs used here, so heparin is enriched at the surface and can more readily interact with blood components compared to chitosan. However, from the RI study, significantly more polysaccharides were released from the NO-releasing surfaces. This may have caused more chitosan in the lower layers of the PEMs to be exposed, resulting in coagulation in the NOreleasing surfaces.

NO is an inhibitor of platelet activation, which is a key step in the coagulation cascade. [63-65] The antiplatelet effects of NO are reversable, and since NO has a short half-life, these effects can be surpassed by pro-coagulation signals quickly. [66, 67] Even though NO can act to inhibit coagulation, it is not surprising that these surfaces did eventually coagulate after all NO was released. In addition, NO has been shown to mediate fibrinogen deposition which may further affect the formation of thrombin and change their susceptibility to heparin [25, 30]. More studies are required to fully understand the mechanisms of why $\mathrm{TiO}_{2} \mathrm{NT}+\mathrm{PEM}$ surfaces completely inhibited coagulation while $\mathrm{TiO}_{2} \mathrm{NT}+\mathrm{PEM}+\mathrm{NO}$ surfaces did not.

\section{Evaluation of clot development and strengthening}

The initial clot formation time $(K)$ reflects the time it takes for the clot to develop and strengthen, which is dependent on the factors such as thrombin and platelets. This typically occurs in 1-3 $\mathrm{min}$ [68]. $\mathrm{TiO}_{2} \mathrm{NT}+\mathrm{PEM}+\mathrm{NO}$ 
Fig. $5 \alpha$-angle of modified surfaces after 15-min and 60-min incubation in human whole blood $(n \geq 5$ batches of surfaces, * indicates $p<0.05$, N/A indicates no endpoint value was provided by TEG during 60-min test). A $\alpha$-angle: $15 \mathrm{~min}$ incubation. B $\alpha$-angle: $60 \mathrm{~min}$ incubation
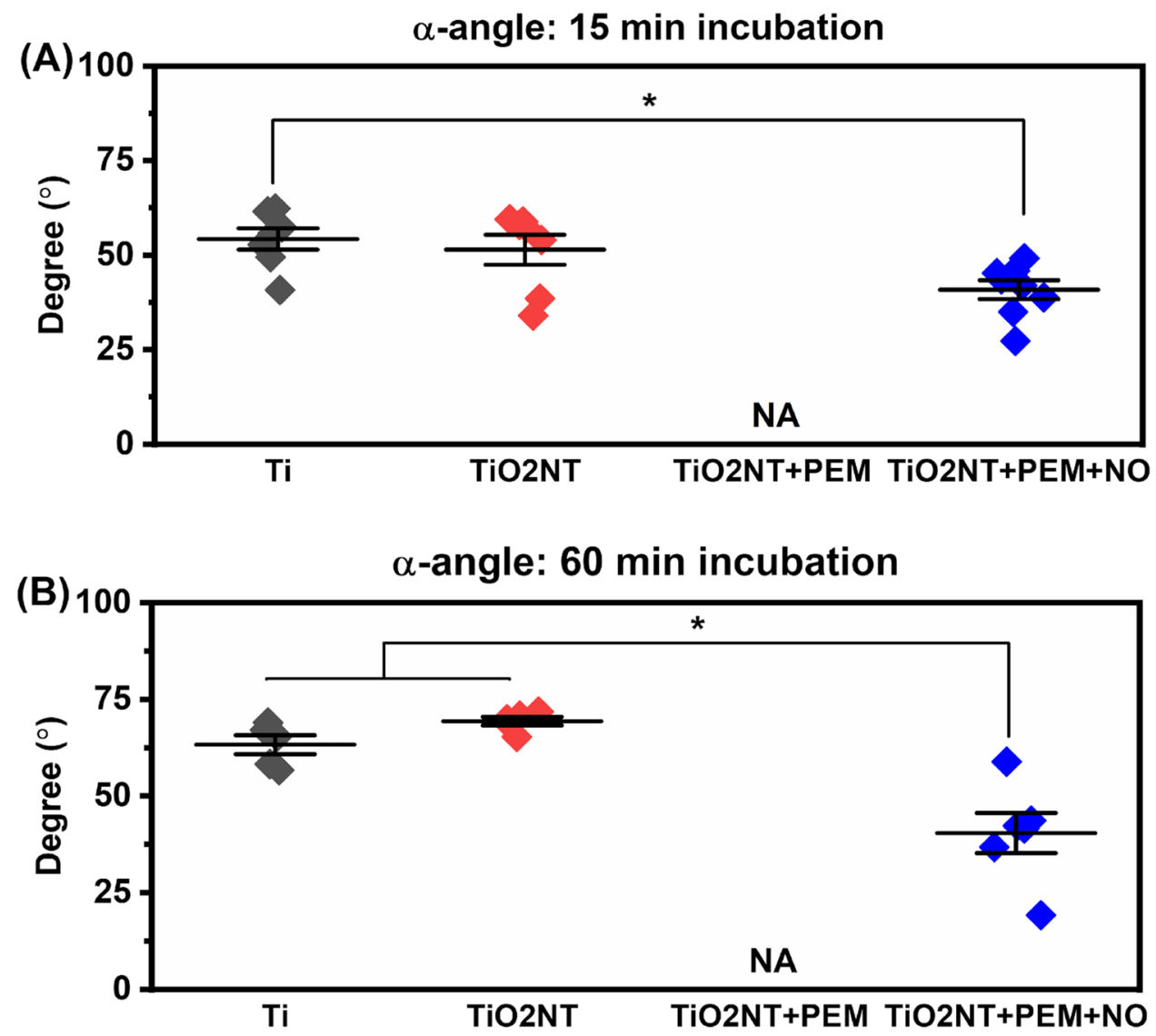

surface $(3.9 \pm 0.8 \mathrm{~min})$ showed an increase in initial clot formation time $(K)$ compared to $\mathrm{Ti}(2.5 \pm 0.6 \mathrm{~min})$ and $\mathrm{TiO}_{2} \mathrm{NT}$ surfaces $(2.6 \pm 0.9 \mathrm{~min})$ after blood was exposed to the surfaces for $15 \mathrm{~min}$ (Fig. 4A). At $60 \mathrm{~min}$, $\mathrm{TiO}_{2} \mathrm{NT}+\mathrm{PEM}+\mathrm{NO}$ surfaces $(5.1 \pm 3.2 \mathrm{~min})$ showed an increase in initial clot formation time $(K)$ compared to $\mathrm{TiO}_{2} \mathrm{NT}$ surfaces $(1.4 \pm 0.2 \mathrm{~min})$, but not Ti surfaces $(1.9 \pm 0.4 \mathrm{~min})($ Fig. $4 \mathrm{~B})$.

The $\alpha$-angle also helps characterize the propagation and strengthening of the clot. The $\alpha$-angle is dependent on fibrin deposition and cross-linking [69]. In healthy blood, $\alpha$-angle ranges from 47 to $78^{\circ}$ [68]. The lower $\alpha$-angle indicates reduced clot formation. The measured $\alpha$-angle of $\mathrm{TiO}_{2} \mathrm{NT}+\mathrm{PEM}+\mathrm{NO}$ surfaces $\left(40.9 \pm 7.0^{\circ}\right)$ was lower compared to $\mathrm{Ti}$ surfaces $\left(54.3 \pm 7.5^{\circ}\right)$, but not significantly different from $\mathrm{TiO}_{2} \mathrm{NT}$ surfaces $\left(51.4 \pm 10.6^{\circ}\right)$ (Fig. $\left.5 \mathrm{~A}\right)$; the $\alpha$-angle of $\mathrm{TiO}_{2} \mathrm{NT}+\mathrm{PEM}+\mathrm{NO}$ surface $\left(40.4 \pm 12.8^{\circ}\right)$ was lower compared to $\mathrm{Ti}$ surfaces $\left(63.3 \pm 5.5^{\circ}\right)$ and $\mathrm{TiO}_{2} \mathrm{NT}$ surfaces $\left(69.4 \pm 2.5^{\circ}\right)$ after 60 -min incubation (Fig. 5B).

Reduced values of $K$ and the $\alpha$-angle were observed for $\mathrm{TiO}_{2} \mathrm{NT}+\mathrm{PEM}+\mathrm{NO}$ surfaces compared to Ti and TiNT surfaces. For these values at both $15 \mathrm{~min}$ and $60 \mathrm{~min}$, $\mathrm{TiO}_{2} \mathrm{NT}+\mathrm{PEM}+\mathrm{NO}$ surfaces also were just outside the normal range for healthy, untreated blood. Ti and $\mathrm{TiO}_{2} \mathrm{NT}$ surfaces were not significantly different from one another and were within the healthy range for all values of $K$ and $\alpha$-angle. Thus, nanotexturing alone was not enough to slow the rate of clot development.

Clot development and strengthening are dependent on the enzymatic factors that produce thrombin which leads to the conversion of fibrinogen to fibrin clot, and the deposition/cross-linking of fibrin on the surface of the growing clot [70-73]. NO is well-known for antiplatelet properties, which could help explain the reduced values of $K$ and $\alpha$-angle [63-65]. However, since NO has a short half-life (millisecond range) $[66,67]$, blood will not contain NO after the transfer of human whole blood from microcentrifuge tubes containing incubated surfaces into TEG cups. Instead, the blood will contain NO oxidation products and probably methemoglobin within red blood cells. Blood incubated with $\mathrm{TiO}_{2} \mathrm{NT}+\mathrm{PEM}+\mathrm{NO}$ surfaces for $15 \mathrm{~min}$ should be exposed to less NO than blood incubated for 60 min, containing less NO oxidation products and methemoglobin, which probably leads to the different results between these two groups.

The heparin-enriched surface and the polysaccharides in the incubation solution would also influence clot development. Heparin works to inhibit coagulation by reversibly binding to antithrombin, thus inhibiting thrombin activity [74]. Heparin acts as a classically recycling catalyst. This 
Fig. 6 MA of modified surfaces after 15-min and 60-min incubation in human whole blood ( $n \geq 5$ batches of surfaces, * indicates $p<0.05$, N/A indicates no endpoint value was provided by TEG during 60 -min test). A Maximal amplitude (MA): 15 min incubation. B Maximal amplitude (MA): $60 \mathrm{~min}$ incubation
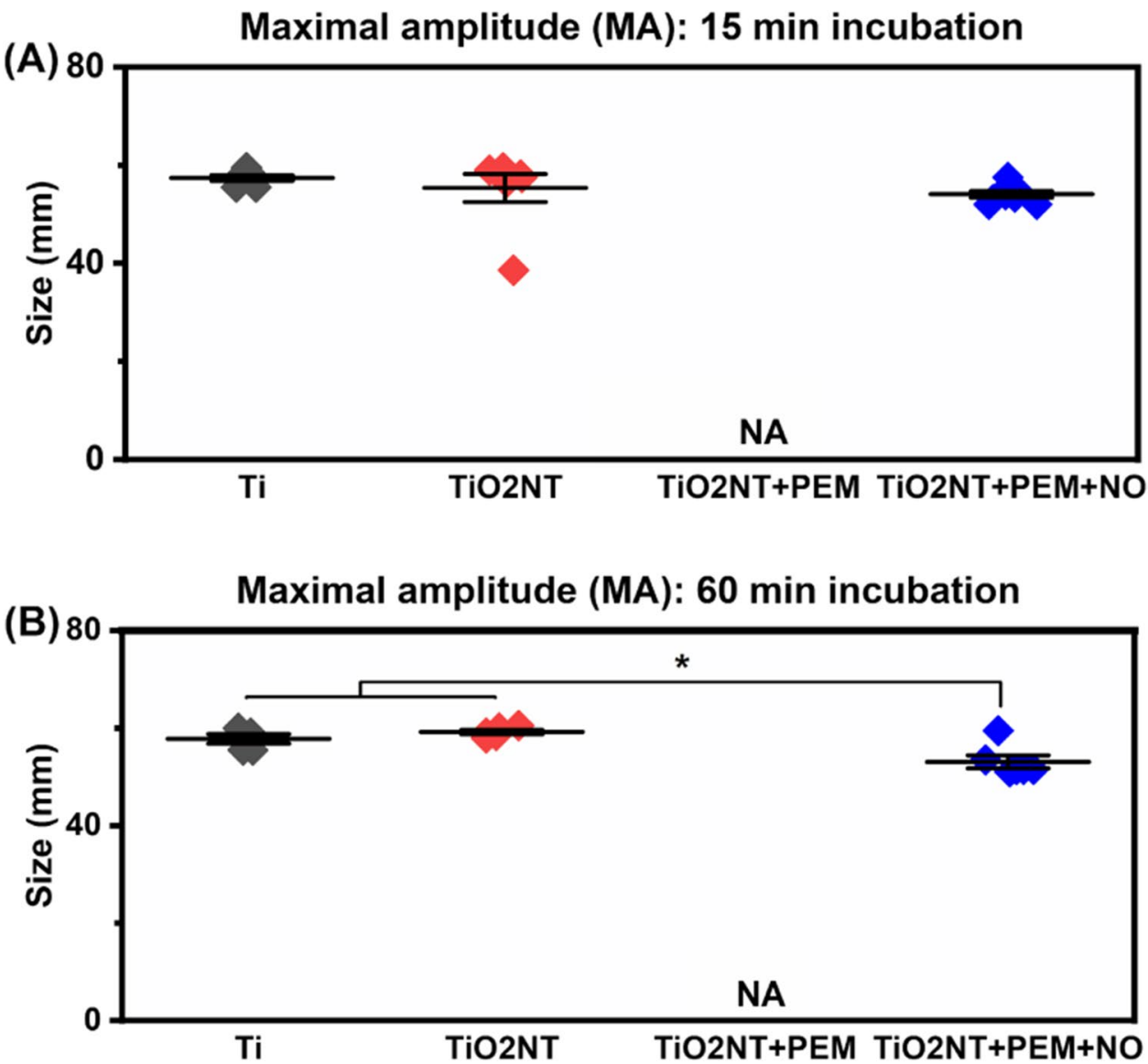

makes it an efficient anticoagulant because a single heparin molecule can continually bind to new antithrombin, thus activating it more. Total inhibition of clot propagation is not observed on these surfaces. This may be a result of several factors as discussed with RI and ATR-FTIR results.

\section{Evaluation of maximal amplitude}

The MA refers to the maximum clot strength and is proportional to fibrinogen concentration [69]. Clot strength values typically range from approximately 49 to $73 \mathrm{~mm}$ [68]. After 15-min incubation in human whole blood, there was no significant difference in the clot strength between $\mathrm{Ti}(57.4 \pm 1.5 \mathrm{~mm}), \mathrm{TiO}_{2} \mathrm{NT}(55.4 \pm 7.5 \mathrm{~mm})$, and $\mathrm{TiO}_{2} \mathrm{NT}+\mathrm{PEM}+\mathrm{NO}(54.1 \pm 1.9 \mathrm{~mm})$ sample conditions (Fig. 6A). The $\mathrm{TiO}_{2} \mathrm{NT}+\mathrm{PEM}+\mathrm{NO}$ surfaces $(53.1 \pm 3.3 \mathrm{~mm})$ had a significantly lower clot strength (MA) compared to Ti surfaces $(57.8 \pm 2.1 \mathrm{~mm})$ and $\mathrm{TiO}_{2} \mathrm{NT}$ $(59.2 \pm 1.0 \mathrm{~mm})$ after $60-\mathrm{min}$ incubation in human whole blood (Fig. 6B).

At this stage, the clot is already developed and the overall clot strength relies on the number of platelets in the clot that are interacting with the fibrin clot deposited on the surfaces. As stated previously, NO is a negative regulator of platelet activation. This may slow down clot development. Once the platelets are activated, the short NO antiplatelet signal from $\mathrm{TiO}_{2} \mathrm{NT}+\mathrm{PEM}+\mathrm{NO}$ surfaces may not be enough to overpower the procoagulant signals during 15-min incubation period compared to 60-min incubation period. Thus, the short NO release does not then have an effect on the activities of the platelets once they become fully activated and reduce clot strength. Additionally, the heparin from the $\mathrm{TiO}_{2} \mathrm{NT}+\mathrm{PEM}+\mathrm{NO}$ surfaces was not able to completely inhibit thrombin production. Once enough thrombin is produced, and fibrin is deposited on the clot, heparin would not have significant influence on clot strength in a short period of time, but would reduce the clot strength if the surfaces were incubated for $60 \mathrm{~min}$.

\section{Conclusions}

In this work, we have shown the ex vivo real-time blood clotting thromboelastographic performance of modified surfaces using human whole blood. Heparin-containing surfaces effectively inhibited or slowed blood clot formation with and without nitrosation. In addition, RI and 
ATR-FTIR results indicated that polysaccharides released into solution during the incubation period and nitrosation process modified both chitosan-TGA and heparin, which would be factors that affect coagulation on modified surface.

Supplementary Information The online version contains supplementary material available at https://doi.org/10.1007/s44164-021-00001-w.

Acknowledgements We sincerely thank Tara Wigmosta and Roberta Maia Sabino for making $\mathrm{TiO}_{2} \mathrm{NT}$ surfaces. We also would like to thank Dr. Alec Lutzke and Jonathan E. Thai for the insightful discussion.

Author contribution The manuscript was written through contributions of all authors. All authors have given approval to the final version of the manuscript.

Funding This work was supported by the National Institutes of Health grant \#1R01HL140301-02 (PI Dr. Melissa M. Reynolds) and by the Assistant Secretary of Defense for the Health Affairs endorsed by the Department of Defense through the Peer Reviewed Medical Research Program - Technology/Therapeutic Development Award, under grant \#W81XWH-18-2-0048 (PI Dr. Andriy I. Batchinsky, co-PI Dr. Melissa M. Reynolds).

Data availability Data available on request from the authors.

\section{Declarations}

Conflict of interest The authors declare no competing interests.

\section{References}

1. Lane WA. Some Remarks on the Treatment of Fractures. BMJ. 1895;1(1790):861-3.

2. Özcan M, Hämmerle C. Titanium as a Reconstruction and Implant Material in Dentistry: Advantages and Pitfalls. Materials (Basel). 2012;5(9):1528-45.

3. Balamurugan A, Rajeswari S, Balossier G, Rebelo AHS, Ferreira JMF. Corrosion aspects of metallic implants - An overview. Mater Corros. 2008;59(11):855-69.

4. Chen Q, Thouas GA. Metallic implant biomaterials. Mater Sci Eng R Reports. 2015;87:1-57.

5. U.S. Food \& Drug Administration, "Biological Responses to Metal Implants," 2019.

6. Gorbet MB, Sefton MV. Biomaterial-associated thrombosis: roles of coagulation factors, complement, platelets and leukocytes. Biomaterials. 2004;25(26):5681-703.

7. Jaffer IH, Fredenburgh JC, Hirsh J, Weitz JI. Medical deviceinduced thrombosis: what causes it and how can we prevent it? J Thromb Haemost. 2015;13(S1):S72-81.

8. Shabalovskaya S, Anderegg J, Van Humbeeck J. Critical overview of Nitinol surfaces and their modifications for medical applications. Acta Biomater. 2008;4(3):447-67.

9. Smith BS, Yoriya S, Grissom L, Grimes CA, Popat KC. Hemocompatibility of titania nanotube arrays. J Biomed Mater Res Part A. 2010;95A(2):350-60.

10. Smith BS, Popat KC. Titania Nanotube Arrays as Interfaces for Blood-Contacting Implantable Devices: A Study Evaluating the Nanotopography-Associated Activation and Expression of Blood Plasma Components. J Biomed Nanotechnol. 2012;8(4):642-58.

11. Shah Z, Masoomi R, Tadros P. Managing Antiplatelet Therapy and Anticoagulants in Patients with Coronary Artery Disease and Atrial Fibrillation. J Atr Fibrillation. 2015;8(4):1318.

12. Thachil J, Gatt A, Martlew V. Management of surgical patients receiving anticoagulation and antiplatelet agents. Br J Surg. 2008;95(12):1437-48.

13. Mehran R, et al. Safety of an Aspirin-Alone Regimen After Intracoronary Stenting With a Heparin-Coated Stent. Circulation. 2003;108(9):1078-83.

14. Di Mario C, et al. Single vs multivessel treatment during primary angioplasty: Results of the multicentre randomised HEpacoat ${ }^{\mathrm{TM}}$ for cuLPrit or multivessel stenting for Acute Myocardial Infarction (HELP AMI) Study. Int J Cardiovasc Intervent. 2004;6(3-4):128-33.

15. Kocsis JF, Llanos G, Holmer E. Heparin-Coated stents. J Long Term Eff Med Implants. 2000;10(1-2):19-45.

16. Lappegård KT, et al. Effect of complement inhibition and heparin coating on artificial surface-induced leukocyte and platelet activation. Ann Thorac Surg. 2004;77(3):932-41.

17. Finn AV, et al. Vascular Responses to Drug Eluting Stents. Arterioscler Thromb Vasc Biol. 2007;27(7):1500-10.

18. Simon-Walker R, et al. Glycocalyx-Inspired Nitric OxideReleasing Surfaces Reduce Platelet Adhesion and Activation on Titanium. ACS Biomater Sci Eng. 2017;3(1):68-77.

19. Hedayati M, Kipper MJ. Atomic force microscopy of adsorbed proteoglycan mimetic nanoparticles: Toward new glycocalyxmimetic model surfaces. Carbohydr Polym. 2018;190:346-55.

20. Hedayati M, Reynolds MM, Krapf D, Kipper MJ. Nanostructured Surfaces That Mimic the Vascular Endothelial Glycocalyx Reduce Blood Protein Adsorption and Prevent Fibrin Network Formation. ACS Appl Mater Interfaces. 2018;10(38):31892-902.

21. Hedayati M, Marruecos DF, Krapf D, Kaar JL, Kipper MJ. Protein adsorption measurements on low fouling and ultralow fouling surfaces: a critical comparison of surface characterization techniques. Acta Biomater. 2020;102:169-80.

22. Sabino RM, Kauk K, Madruga LYC, Kipper MJ, Martins AF, Popat KC. Enhanced hemocompatibility and antibacterial activity on titania nanotubes with tanfloc/heparin polyelectrolyte multilayers. J Biomed Mater Res Part A. 2020;108(4):992-1005.

23. da Câmara PCF, et al. Polyelectrolyte multilayers containing a tannin derivative polyphenol improve blood compatibility through interactions with platelets and serum proteins. Mater Sci Eng C. 2020;112:110919.

24. Rosselli M, Keller PJ, Dubey RKK, Keller RJ, Dubey RKK. Role of nitric oxide in the biology, physiology and pathophysiology of reproduction. Hum Reprod Updat. 1998;4(1):3-24.

25. Lantvit SM, Barrett BJ, Reynolds MM. Nitric oxide releasing material adsorbs more fibrinogen. J Biomed Mater Res - Part A. 2013;101(11):3201-10.

26. Zang Y, Popat KC, Reynolds MM. Nitric oxide-mediated fibrinogen deposition prevents platelet adhesion and activation ARTICLES YOU MAY BE INTERESTED IN. Biointerphases. 2018;13(6):E403.

27. Major TC, et al. The attenuation of platelet and monocyte activation in a rabbit model of extracorporeal circulation by a nitric oxide releasing polymer. Biomaterials. 2010;31(10):2736-45.

28. Damodaran VB, Leszczak V, Wold KA, Lantvit SM, Popat KC, Reynolds MM. Anti-thrombogenic properties of a nitric oxidereleasing dextran derivative: evaluation of platelet activation and whole blood clotting kinetics. RSC Adv. 2013;3(46):24406-14.

29. Pant J, Goudie MJ, Hopkins SP, Brisbois EJ, Handa H. Tunable Nitric Oxide Release from S-Nitroso-N-acetylpenicillamine via 
Catalytic Copper Nanoparticles for Biomedical Applications. ACS Appl Mater Interfaces. 2017;9(18):15254-64.

30. Zang Y, Popat KC, Reynolds MM. Nitric oxide-mediated fibrinogen deposition prevents platelet adhesion and activation. Biointerphases. 2018;13(6):06E403.

31 Peng HT. Thromboelastographic study of biomaterials. J Biomed Mater Res Part B Appl Biomater. 2010;94B(2):469-85.

32. Roberts TR, Leslie DC, Cap AP, Cancio LC, Batchinsky AI. Tethered-liquid omniphobic surface coating reduces surface thrombogenicity delays clot formation and decreases clot strength ex vivo. J Biomed Mater Res Part B Appl Biomater. 2020;108(2):496-502.

33. Hawker MJ, Olver CS, Fisher ER. Modification of a commercial thromboelastography instrument to measure coagulation dynamics with three-dimensional biomaterials. Biointerphases. 2016;11(2):29602.

34. Ouyang Y, et al. Qualitative and quantitative analysis of heparin and low molecular weight heparins using size exclusion chromatography with multiple angle laser scattering/refractive index and inductively coupled plasma/mass spectrometry detectors. J Chromatogr A. 2017;1522:56-61.

35. Sorkin JA, Hughes S, Soares P, Popat KC. Titania nanotube arrays as interfaces for neural prostheses. Mater Sci Eng C. 2015;49:735-45

36. Yao C, Webster TJ. Anodization: a promising nano-modification technique of titanium implants for orthopedic applications. J Nanosci Nanotechnol. 2006;6(9-10):2682-92.

37. Minagar S, Wang J, Berndt CC, Ivanova EP, Wen C. Cell response of anodized nanotubes on titanium and titanium alloys. J Biomed Mater Res Part A. 2013;101A(9):2726-39.

38. Damodaran VB, Bhatnagar D, Leszczak V, Popat KC. Titania nanostructures: a biomedical perspective. RSC Adv. 2015;5(47):37149-71.

39. Popat KC, Eltgroth M, LaTempa TJ, Grimes CA, Desai TA. Titania nanotubes: A novel platform for drug-eluting coatings for medical implants? Small. 2007;3(11):1878-81.

40. Cowden K, Dias-Netipanyj MF, Popat KC. Effects of titania nanotube surfaces on osteogenic differentiation of human adiposederived stem cells. Nanomedicine. 2019;17:380-90.

41. Vaughn MW, Kuo L, Liao JC. Estimation of nitric oxide production and reaction rates in tissue by use of a mathematical model. Am J Physiol - Hear Circ Physiol. 1998;274(6):43-6.

42. Skrzypchak AM, et al. Effect of varying nitric oxide release to prevent platelet consumption and preserve platelet function in an in vivo model of extracorporeal circulation. Perfusion. 2007;22(3):193-200.

43. Lutzke A, Pegalajar-Jurado A, Neufeld BH, Reynolds MM. Nitric oxide-releasing S-nitrosated derivatives of chitin and chitosan for biomedical applications. J Mater Chem B. 2014;2(42):7449-58.

44. Shively JE, Conrad HE. Formation of Anhydrosugars in the Chemical Depolymerization of Heparin. Biochemistry. 1976;15(18):3932-42.

45. Allison CL, Lutzke A, Reynolds MM. Examining the effect of common nitrosating agents on chitosan using a glucosamine oligosaccharide model system. Carbohydr Polym. 2019;203:285-91.

46. Vilar RE, et al. Nitric oxide degradation of heparin and heparan sulphate. Biochem J. 1997;324(2):473-9.

47. Vlcek JR, Hedayati M, Melvin AC, Reynolds MM, Kipper MJ. Blood-compatible materials: vascular endothelium-mimetic surfaces that mitigate multiple cell-material interactions. Adv Healthc Mater. 2021;10(7):2001748.
48. Oduah E, Linhardt R, Sharfstein S. Heparin: past, present, and future. Pharmaceuticals. 2016;9(3):38.

49. Linhardt R, Murugesan S, Xie J. Immobilization of heparin: approaches and applications. Curr Top Med Chem. 2008;8(2):80-100.

50. Oliver WC. Anticoagulation and coagulation management for ECMO. Semin Cardiothorac Vasc Anesth. 2009;13(3):154-75.

51. Brandenberg G, Leibrock LG, Shuman R, Malette WG, Quigley H. Chitosan: a new topical hemostatic agent for diffuse capillary bleeding in brain tissue. Neurosurgery. 1984;15(1):9-13.

52. Rao SB, Sharma CP. Use of chitosan as a biomaterial: studies on its safety and hemostatic potential. J Biomed Mater Res. 1997;34(1):21-8.

53. Benesch J, Tengvall P. Blood protein adsorption onto chitosan. Biomaterials. 2002;23(12):2561-8.

54. Okamoto Y, Yano R, Miyatake K, Tomohiro I, Shigemasa Y, Minami S. Effects of chitin and chitosan on blood coagulation. Carbohydr Polym. 2003;53(3):337-42.

55. Wedmore I, McManus JG, Pusateri AE, Holcomb JB. A special report on the chitosan-based hemostatic dressing: experience in current combat operations. J Trauma - Inj Infect Crit Care. 2006;60(3):655-8.

56. Ong SY, Wu J, Moochhala SM, Tan MH, Lu J. Development of a chitosan-based wound dressing with improved hemostatic and antimicrobial properties. Biomaterials. 2008;29(32):4323-32.

57. Hattori H, Ishihara M. Changes in blood aggregation with differences in molecular weight and degree of deacetylation of chitosan. Biomed Mater. 2015;10(1):015014.

58. Mirzadeh H, Yaghobi N, Amanpour S, Ahmadi H, Mohagheghi MA, Hormozi F. Preparation of chitosan derived from shrimp's shell of Persian gulf as a blood hemostasis agent. Iran Polym J. 2002;11(1):63-8.

59. Chou TC, Fu E, Wu CJ, Yeh JH. Chitosan enhances platelet adhesion and aggregation. Biochem Biophys Res Commun. 2003;302(3):480-3.

60. Sagnella S, Mai-Ngam K. Chitosan based surfactant polymers designed to improve blood compatibility on biomaterials. Colloids Surfaces B Biointerfaces. 2005;42(2):147-55.

61. Lord MS, Cheng B, McCarthy SJ, Jung MS, Whitelock JM. The modulation of platelet adhesion and activation by chitosan through plasma and extracellular matrix proteins. Biomaterials. 2011;32(28):6655-62.

62. Hu Z, Zhang D-Y, Lu S-T, Li P-W, Li S-D. Chitosan-based composite materials for prospective hemostatic applications. Mar Drugs. 2018;16(8):273.

63. Radomski MW, Palmer RM, Moncada S. Endogenous nitric oxide inhibits human platelet adhesion to vascular endothelium. Lancet. 1987;330(8567):1057-8.

64. Radomski MW, Moncada S. The biological and pharmacological role of nitric oxide in platelet function. Adv Exp Med Biol. 1993;344:251-64.

65. Fleser PS, et al. Nitric oxide-releasing biopolymers inhibit thrombus formation in a sheep model of arteriovenous bridge grafts. J Vasc Surg. 2004;40(4):803-11.

66. Archer S. Measurement of nitric oxide in biological models FASEB J. 1993;7(2):349-60.

67. Hakim TS, Sugimori K, Camporesi EM, Anderson G. Half-life of nitric oxide in aqueous solutions with and without haemoglobin. Physiol Meas. 1996;17(4):267-77. 
68. Scarpelini $\mathrm{S}$, et al. Normal range values for thromboelastography in healthy adult volunteers. Braz J Med Biol Res. 2009;42(12):1210-7.

69. Othman M, Kaur H. Thromboelastography (TEG). Methods Mol Biol. 2017;1646:533-43.

70. Hoffman M. Remodeling the blood coagulation cascade. J Thromb Thrombolysis. 2003;16(1-2):17-20.

71 Roberts H, Hoffman M, Monroe D. A Cell-Based Model of Thrombin Generation. Semin Thromb Hemost. 2006;32(S 1):032-8.
72. Mackman N, Tilley RE, Key NS. Role of the Extrinsic Pathway of Blood Coagulation in Hemostasis and Thrombosis. Arterioscler Thromb Vasc Biol. 2007;27(8):1687-93.

73. Smith SA. The cell-based model of coagulation. J vet Emerg Crit Care. 2009;19(1):3-10.

74. Sanchez J, Elgue G, Riesenfeld J, Olsson P. Studies of adsorption, activation, and inhibition of factor XII on immobilized heparin. Thromb Res. 1998;89(1):41-50. 